\title{
Laparoscopic versus open pylorus-preserving pancreatoduodenectomy. The first meta-analyse of retrospective matched cases $^{1}$
}

\author{
Liwei Pang', Jing Kong', Yuwen Wang", Yan Zhang'
}

'PhD, Department of Biliary and Minimally Invasive Surgery, China Medical University Shengjing Hospital Shenyang, Liaoning, China. Acquisition, analysis and interpretation of data; statistical analysis, manuscript preparation and writing; critical revision; final approval.

"PhD, Department of Surgery, The Sixth People's Hospital of Shenyang, Liaoning, China. Acquisition, analysis and interpretation of data.

\section{Abstract}

Purpose: To compare the safety, feasibility, and short-term clinical benefits of laparoscopic pylorus-preserving pancreaticoduodenectomy (L-PPPD) to open pylorus-preserving pancreaticoduodenectomy (O-PPPD) through retrospective matched cases.

Methods: Web of Science, Cochrane, PubMed, CNKI were searched systematically identify studies published between January and December 2017 comparing L-PPPD to O-PPPD. The meta-analysis was performed by using Review Manager 5.3.

Results: Two studies matched the selection criteria, including 108 (50\%) cases of laparoscopic pylorus-preserving pancreaticoduodenectomy and $108(50 \%)$ cases of open pyloruspreserving pancreaticoduodenectomy. None of the included studies were randomized, which were both retrospective matched cases. There was no difference in the incidence of postoperative pancreatic fistula, blood loss, diet start and lymph nodes. However, L-PPPD has a shorter hospital stay $(p=0.0003)$ and O-PPPD has a shorter operative time $(p=0.02)$ and tend to decrease the delayed gastric emptying.

Conclusions: The perioperative safety of laparoscopic surgery, which also has advantages of minimal invasion and shorter hospital stay, is comparable to that of open surgery. Laparoscopic surgery could be operated if the patients matched the indication and operation difficulty is not so great. However, blind pursuits of L-PPPD should be restrained because there is no essential difference between these two in terms of feasibility, safety and short-term complication.

Key words: Laparoscopy. Pylorus. Pancreaticoduodenectomy. Meta-Analysis. 


\section{- Introduction}

In 1935, Whipple ${ }^{1}$ first reintroduced pancreatoduodenectomy (PD), which is the only potentially effective treatment for periampullary cancer so far ${ }^{2}$. However, the PD is still associated with high postoperative morbidity rates and mortality rates because of clinical and biological characteristics of periampullary carcinoma despite the progress and proficiency ${ }^{3}$. With the development of surgical technology and many scholars had tried to improve PD in the hope of a better prognosis, the laparoscopic pylorus-preserving pancreatoduodenectomy(L-PPPD) was firstly reported by Gagner ${ }^{4}$ while there was still some controversy that the the safety, feasibility and short-term clinical benefits of the L-PPPD. To our knowledge, there is few articles involved L-PPPD and O-PPPD and no metaanalyse compared it. Based on a great deal of the published evidence and the conflicting conclusion, the purpose of the this study was to systematically review the literature that have compared L-PPPD with O-PPPD and to meta-analyze the best evidence available, to provide high-quality data for clinical practice the first time.

\section{Methods}

This study was designed according to the Preferred Reporting Items for Systematic Reviews and Meta-Analyses (PRISMA) guidelines ${ }^{5}$. We searched medical databases in which articles involved L-PPPD versus O-PPPD. This search strategy was designed and executed by an experienced information specialist and reviewed by 2 writers (Liwei Pang and Jing Kong).

\section{Literature strategy}

A detailed literature search was performed in online databases including Web of Science (244), Cochrane (334),
PubMed (61), CNKI (43) (last search date: October 30, 2017), without restriction to regions, publication types, or languages. The following terms were included "laparoscopic/ laparoscopy/minimally invasive, pyloruspreserving pancreatoduodenectomy". When similar reports describing the same population were published, the most recent or complete report was used. The research was conducted independently by Liwei Pang and Jing Kong, subsequently all the authors compared their results. References from the articles were investigated manually. Any differences were resolved by consensus. This review adhered to the guidelines outlined in the PRISMA statement.

\section{Study selection}

Included were studies comparing L-PPPD (either laparoscopic, or hybrid PD) with O-PPPD reporting on at least 10 patients in all age groups and that had at least one of the meaningful conclusions. The exclusion criteria were noncomparable studies, nonhuman studies, experimental trials, review articles, editorials, letters and case reports, and articles not reporting the outcomes of interest.

\section{Data extraction}

The following data were extracted: name of authors; study design; number of patients included in the laparoscopic or hybrid; age; body mass index (BMI); operative time; estimated blood loss; diet start time; postoperative complications; pancreatic fistula; delayed gastric emptying; number of lymph nodes harvested; postoperative hospital stay.

\section{Quality assessment and statistical analysis}

Studies were rated for the level of evidence provided according to criteria by the Centre for Evidence-Based Medicine in Oxford, UK. The methodological quality 
was assessed by the modified NewcastleOttawa scale ${ }^{6}$, consisting of 3 factors: patient selection, comparability of the study groups, and assessment of outcome. A score of 0 to 9 (allocated as stars) was allocated to each study, and observational studies achieving Z6 stars were considered to be of high quality.

We used Review Manager 5.3 (Cochrane collaboration, Oxford, England) for all statistical analyses. Considering that patients were selected by different surgical teams and operated in different centers; we chose the random-effects model to assess this heterogeneity. 12 was used for heterogeneity assessment, and values of more than $50 \%$ were considered significant. Dichotomous variables were analyzed and assessed with an odds ratio (OR); a value of less than 1 favored the laparoscopic cohort, while values of $\mathrm{P}<0.05$ and $95 \%$ confidence intervals $(\mathrm{Cls})$ without the value of 1 supported the statistical significance of odds ratio (OR). Continuous variables analyzed with the weighted mean difference (WMD). The Mantel-Haenszel method was used to combine the OR for the outcomes of interest; Peto OR was used when necessary. This study was performed according to the Preferred Reporting Items for Systematic reviews (PRISMA) ${ }^{5}$ guidelines.

\section{Results}

The literature search referred to 682 studies initially. No other eligible studies were found from other sources. At first time, 10 potential meaningful articles were included for a full-text browsing after looking through their titles and abstracts. Of these, we excluded 1 article $^{7}$ after look through the whole paper ${ }^{7,8}$ because they are from the same institution. U. F. Wellne et al. ${ }^{9}$ was excluded because the data was not impactful and the authors could not provide information in detail. We also excluded another study ${ }^{10}$ because there was no comparison in it. The rest 5 are case report. Finally, this left a total of 2 studies $^{8,11}$ representing 216 patients for inclusion in the meta-analysis. The Figure 1 illustrates the PRISMA flow chart of literature search strategies.

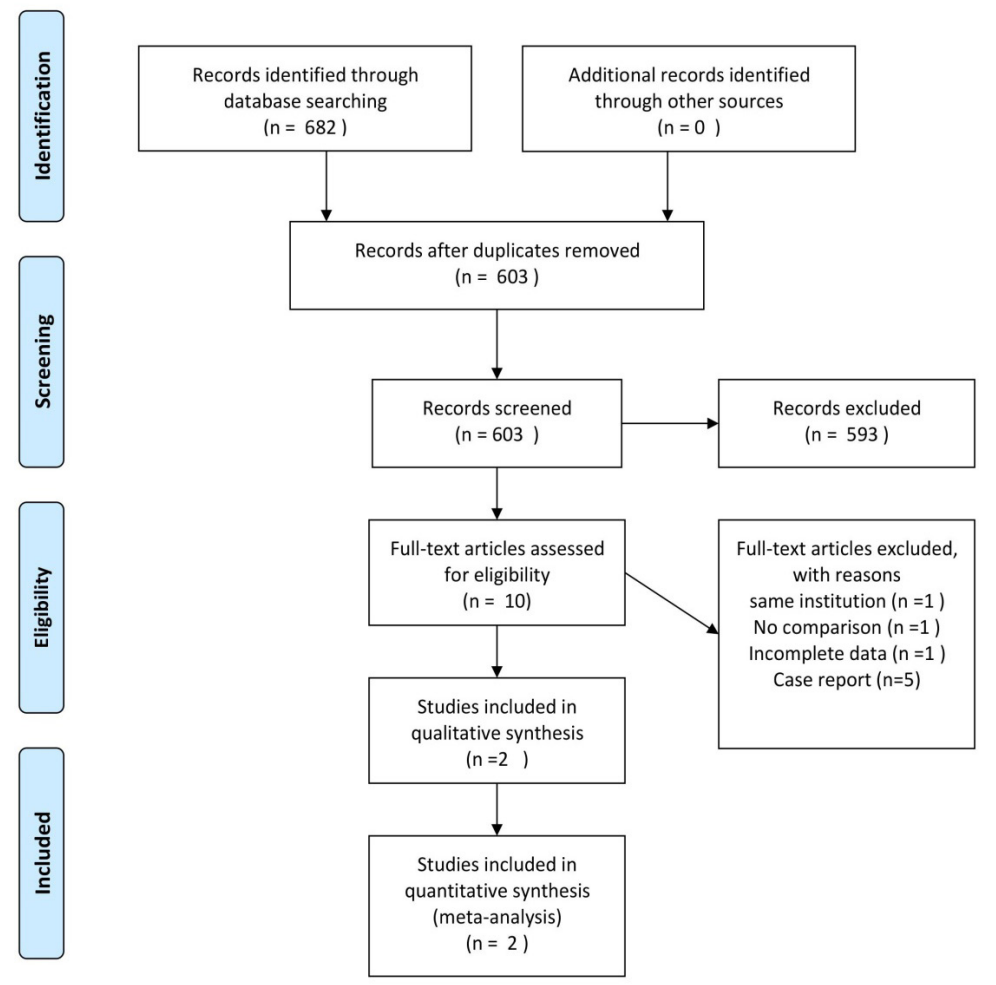

Figure 1 - Preferred reporting items for systematic reviews and meta-analyses (PRISMA) flow diagram. 


\section{Meta-analysis}

The meta-analysis determined that L-PPPD was associated with a longer operative time (MD: $119.74 \mathrm{~min}$; 95\% Cl 92.76-146.72 $\left.\min ; \mathrm{I}^{2}=81 \% ; \mathrm{P}<0.01\right)$ and hospital stay (MD: -1.53day; $95 \% \mathrm{Cl}-3.05$ to $0 ; \mathrm{I}^{2}=92 \% ; \mathrm{P}=0.05$ ) (Figure 2). Among all studies, they all had tried to control variable such as age, BMI, ASA (Figure 3). The meta-analysis also showed the similar results in blood loss (MD: $13.52 \mathrm{ml}$; 95\%
$\left.\mathrm{Cl}-94.36-121.4 \mathrm{~min} ; \mathrm{I}^{2}=1 \% ; \mathrm{P}=0.81\right)$, diet start (MD: -0.26 day; $95 \% \mathrm{Cl}-0.99-0.48 \mathrm{~min} ; \mathrm{I}^{2}=$ $54 \%$; $P=0.49$ ), lymph nodes (MD: $-1.26 ; 95 \% \mathrm{Cl}$ $\left.-3.76-123 \mathrm{~min} ; \mathrm{I}^{2}=50 \% ; \mathrm{P}=0.32\right)$, respectively (Figure 4 ). In the meta-analysis, there were no significant differences between the two procedures about postoperative complication (OR: 0.95; 95\% Cl 0.52-1.74; $\mathrm{I}^{2}=0 \%$; $\mathrm{P}=0.88$ ), pancreatic fistula (OR: $1 ; 95 \% \mathrm{Cl} 0.36-2.78 ; I^{2}$ $=0 \% ; \mathrm{P}=1.0)$. Delayed gastric emptying tended to be decreased in L-PPPD (OR:0.58; $95 \% \mathrm{Cl}$ $0.18-1.94 ; I^{2}=22 \% ; P=0.38$ ) (Figure 5).

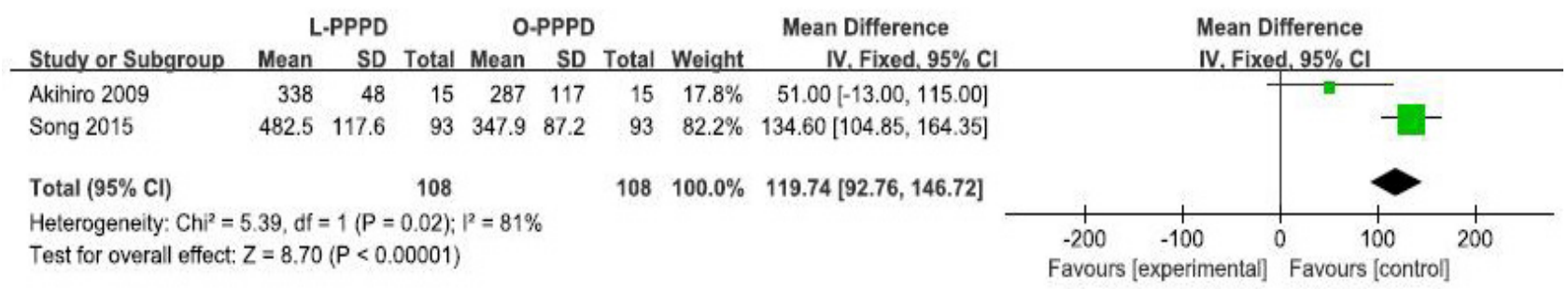

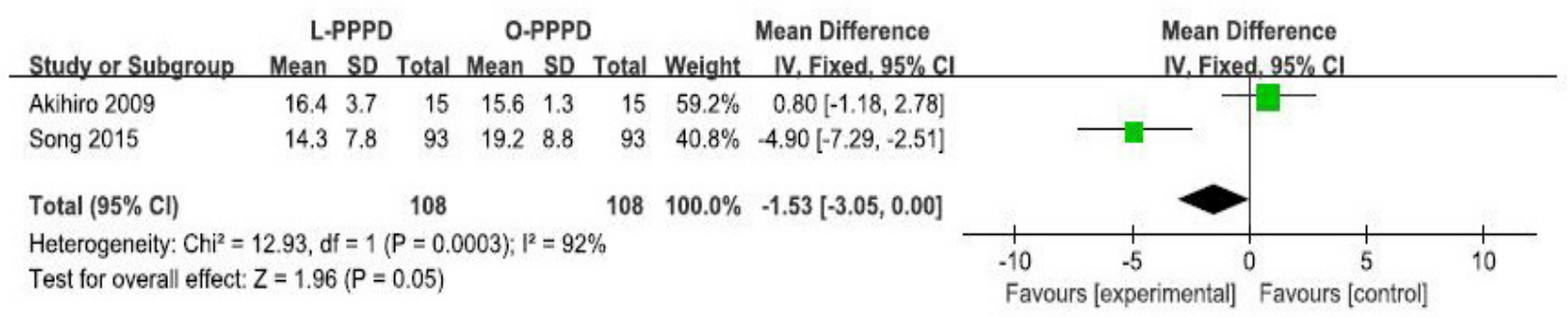

Figure 2 -Operative time and hospital stay L-PPPD versus O-PPPD. 95\% $\mathrm{Cl}$ and $\mathrm{df}$. 


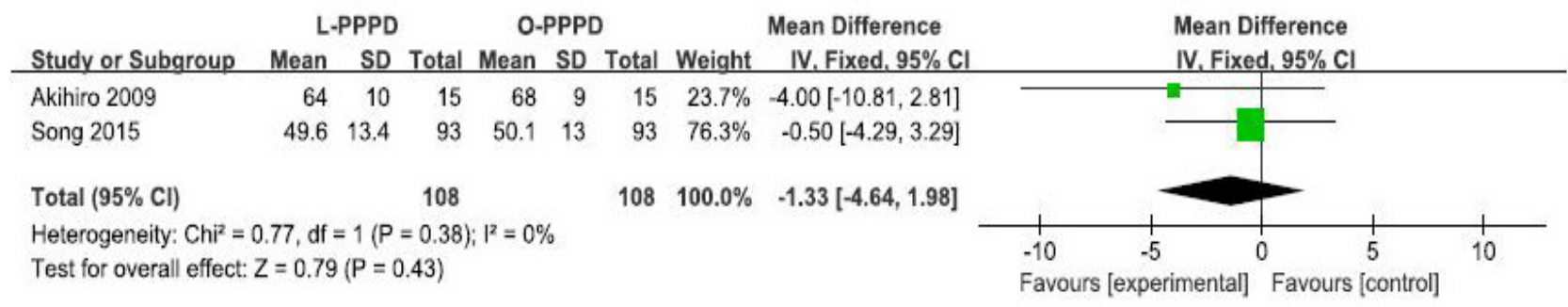

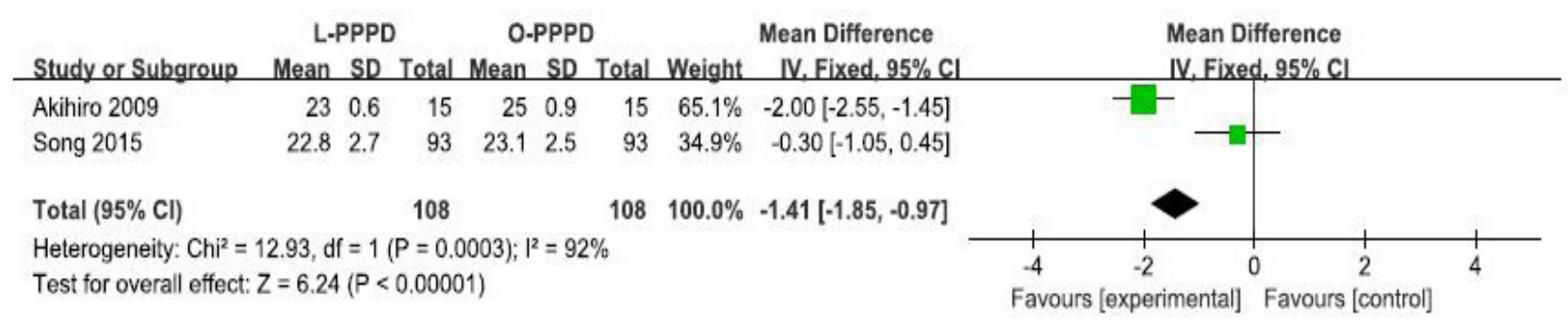

Figure 3 - Age and BMI controlled comparing L-PPPD versus O-PPPD. 95\% $\mathrm{Cl}$ and $\mathrm{df}$.

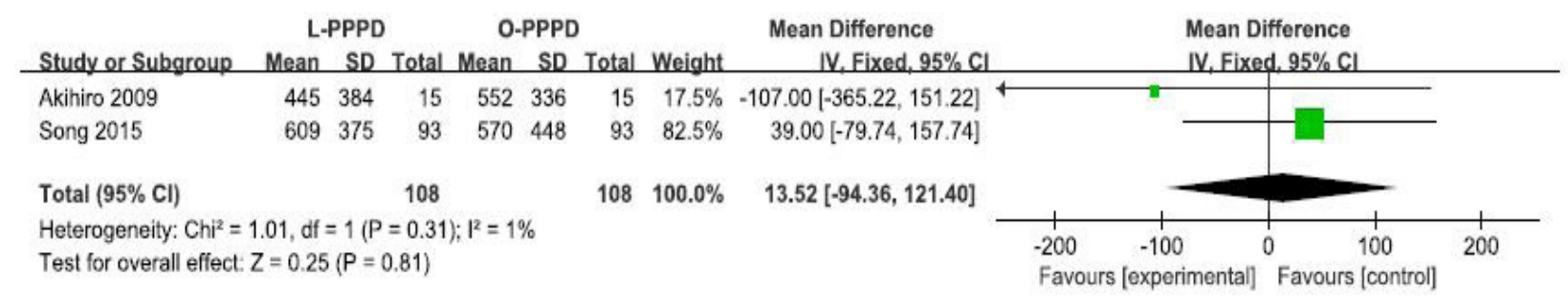

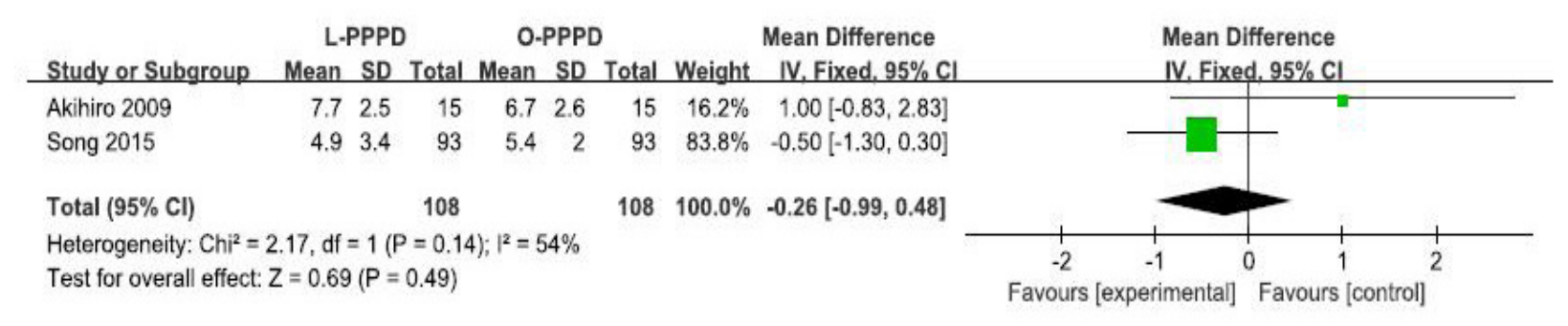

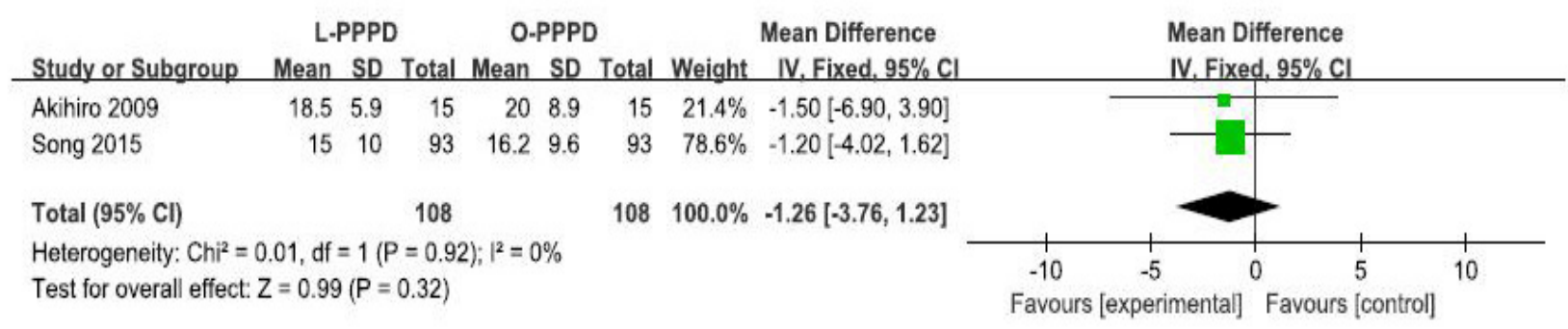

Figure 4 - Blood loss and diet start and lymph nodes comparing L-PPPD versus O-PPPD. 95\% Cl and df. 


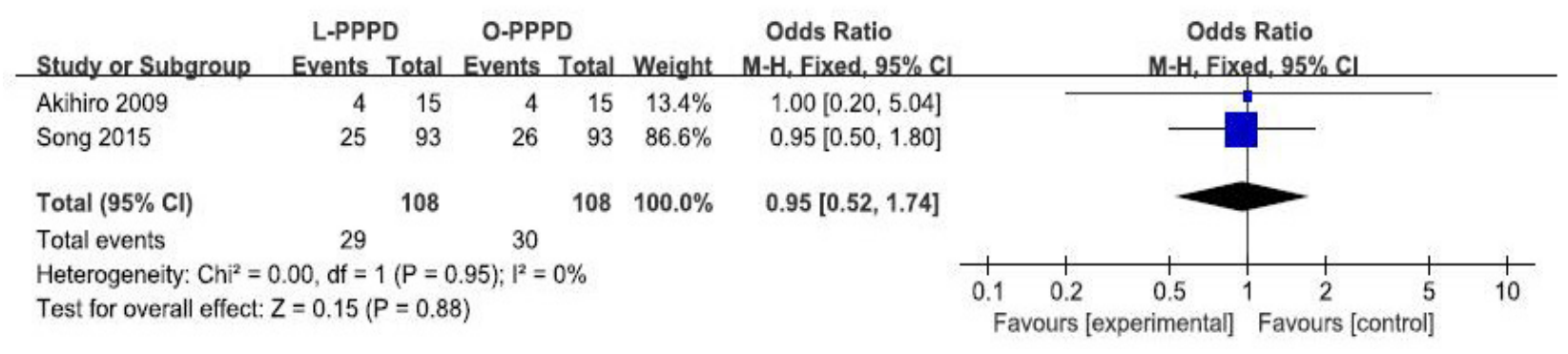

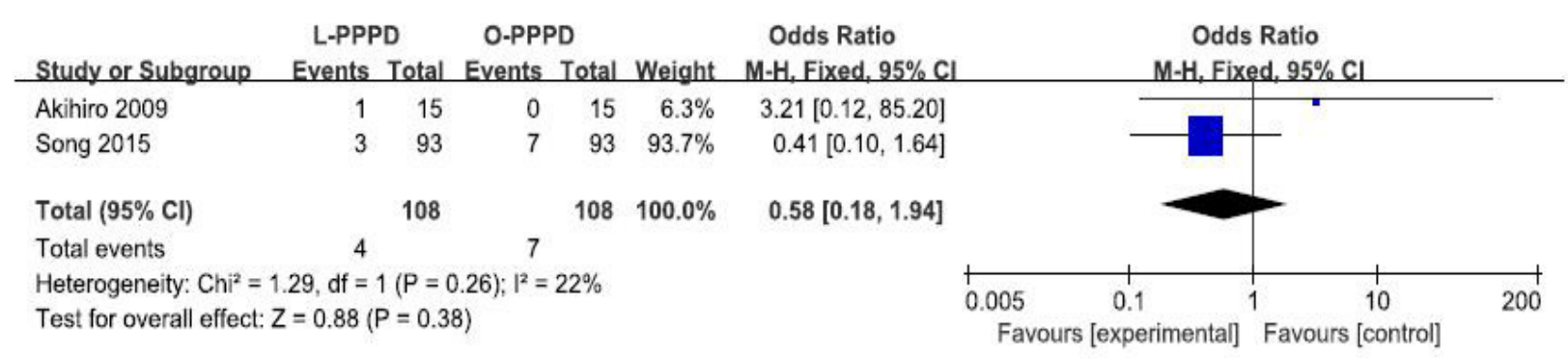

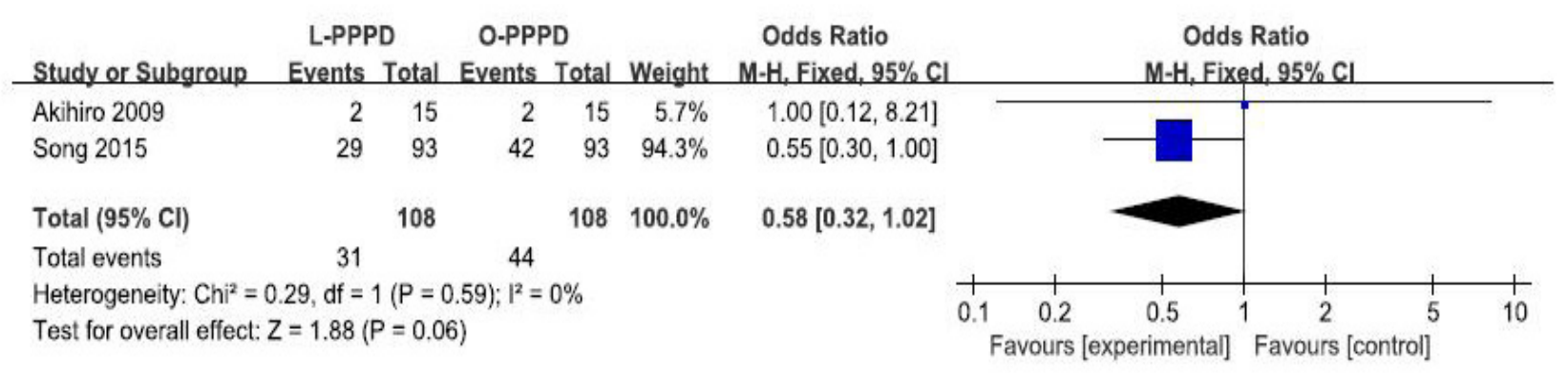

Figure 5 - Postoperative complication and pancreatic fistula and DGE comparing L-PPPD versus O-PPPD. 95\% $\mathrm{Cl}$ and $\mathrm{df}$.

\section{Discussion}

Technological progress in recent decades has brought about great development of laparoscopic techniques. However, PD still remains a arduous challenge and since when Gagner performed the first laparoscopic PD. Although laparoscopy has the visual advantage of a magnified view, it is still a timeconsuming surgery because of the procedural complexities, such as difficulties in exposing the retroperitoneal spaces, control blood loss or the major vasculature, and complex suture techniques ${ }^{12}$. In addition, some meta-analysis studies ${ }^{12-15}$ that laparoscopic
PD compared to open surgery had shown extremely long operating time in the absence of significant benefits and a similar safety, feasibility. Meanwhile, pylorus-preserving pancreatoduodenectomy could improve the quality of life and reduce the incidence of anastomotic complications in postoperative patients compared to traditional PD. However, the outcomes of literature discussed L-PPPD and O-PPPD are not in complete accord, even in opposite, such as blood loss ${ }^{8,11}$. To the best of our knowledge, this is the first meta-analysis that compares these two. It included 216 patients, 108 (50\%) of which underwent L-PPPD and 108 (50\%) of which underwent O-PPPD. 
In sum, our meta-analysis did not detect any statistically significant differences in incidence of postoperative pancreatic fistula, time of diet start, lymph nodes major morbidity, blood loss. L-PPPD showed a statistically significant reduced hospital length of stay.

The main disadvantage of L-PPPD was the duration of operation caused to inefficiency. The longer operative time was related to multiple reasons, including the longer learning curve, difficulty in accessing and exposure of the pancreas, a technically demanding reconstruction of the biliary and pancreatic remnants, hemorrhage control from major vasculature ${ }^{13}$. Some articles holds intraoperative blood loss was lower during laparoscopic than open. This is often attributed to the magnified view supplied by laparoscopy which opens the surgeon's eyes of the structures surrounding the specimen, allowing precise resection along appropriate levels $s^{2,13,16}$. But those with expected bleeding or difficulty in surgery were directly decided to receive an open PD during preoperative assessment, which obviously led to selection bias. Our metaanalysis don't show a optimistic point on blood loss maybe due to the long learning curve and early-period group of L-PPPD may be more easy to blood loss as a result of inexperience. Despite the advances in surgical technique, pancreatic resection is still associated with a high level of morbidity because of pancreatic fistula and delayed gastric emptying. No clinically significant advantages in the L-PPPD had showed either in the early or late period. DGE tended to be decreased in L-PPPD because laparoscopic surgery reduced the frequency of surgical-site infections and occurrence of postoperative adhesion ${ }^{17}$. Although long-term oncologic outcomes are not addressed in these studies, lymph node retrieval are used as indicators of the oncologic adequacy of laparoscopic surgery. Lymph node staging is a very relevant prognostic factor for pancreatic cancer patients. However, it is depressed that there was no obvious difference in these two. Our meta-analysis showed L-PPPD has a shorter length of stay. A short hospital stay theoretically can reduce the pain of the patients and expense of the whole treatment but minimally invasive surgery is known to be associated with higher intraoperative costs. The cost-effectiveness of L-PPPD is worth considering.

The advantage of this review is that it provides a comprehensive comparison of L-PPPD with O-PPPD. To our knowledge, this meta-analysis is the first to explore these two using matched case controlling the age, BMI, ASA, et al. Of course, this meta-analysis has some limitations, which must be worth to note. First, there were no RCT and selection bias could be a big problem because of the retrospective matched cases such as the choice of patients, the assessment of complication such as pancreatic fistula, delayed gastric emptying. Second, the small number of patients and studies decreased the reliability although we had searched several databases. The quantity of this study was not large enough, and the results need more effective evidence in further high-quality trials. Moreover, high statistical heterogeneity was found among included studies, which even reached $90 \%$ for some parameters limiting the quality of results. Furthermore, we did not analyze the surgical technique such as types of pancreatic and biliary anastomoses, which must influence the complication. And we didn't discuss the prognosis and long-term complications about L-PPPD and O-PPPD.

\section{Conclusions}

This meta-analysis reveals the laparoscopic pylorus-preserving pancreaticoduodenectomy (L-PPPD) has minimal invasion and shorter hospital stay while the operative time may prolong. 
The time of diet start, postoperative complications, lymph nodes have no significant difference. Laparoscopic pylorus-preserving pancreatoduodenectomy can be a reasonable alternative to open pylorus-preserving pancreatoduodenectomy with potential advantages once the operators grasp the points of laparoscopic skills. However, blind pursuits of L-PPPD should be restrained because of the long learning curve and cost-effectiveness.

\section{References}

1. Whipple AO, Parsons WB, Mullins CR. Treatment of carcinoma of the ampulla of Vater. Ann Surg. 1935;102:763-79. PMID: 17856666.

2. de Rooij T, Lu MZ, Steen MW, Gerhards MF, Dijkgraaf MG, Busch OR, Lips DJ, Festen S, Besselink MG; Dutch Pancreatic Cancer Group. Minimally invasive versus open pancreatoduodenectomy systematic review and meta-analysis of comparative cohort and registry studies. Ann Surg. 2016;264(2):25767. doi: $10.1097 /$ SLA.0000000000001660.

3. Elberm H, Ravikumar R, Sabin C, Abu Hilal M, Al-Hilli A, Aroori S, Bond-Smith G, Bramhall S, Coldham C, Hammond J, Hutchins R, Imber C, Preziosi G, Saleh A, Silva $M$, Simpson J, Spoletini G, Stell D, Terrace J, White S, Wigmore S, Fusai G. Outcome after pancreaticoduodenectomy for T3 adenocarcinoma: a multivariable analysis from the UK Vascular Resection for Pancreatic Cancer Study Group. Eur J Surg Oncol. 2015;41:1500-7. doi: 10.1016/j. ejso.2015.08.158.

4. Gagner M, Pomp A. Laparoscopic pyloruspreserving pancreatoduodenectomy. Surg Endosc. 1994;8:408-10. PMID: 7915434.

5. Liberati A, Altman DG, Tetzlaff J, Mulrow C, Gøtzsche PC, loannidis JP, Clarke M, Devereaux PJ, Kleijnen J, Moher D. The PRISMA statement for reporting systematic reviews and meta-analyses of studies that evaluate health care interventions: explanation and elaboration. Ann Intern Med. 2009;151(4):W65-94. PMID: 19622512.

6. Wells GA, Shea B, O'Connell D. The Newcastle-Ottawa Scale (NOS) for assessing the quality of nonrandomized studies in meta-analyses. Available from: http://www. ohri.ca/programs/clinical_epidemiology/ oxford.asp.

7. Kim SC, Song KB, Jung YS, Kim YH, Park DH, Lee SS, Seo DW, Lee SK, Kim MH, Park KM, Lee YJ. Short-term clinical outcomes for 100 consecutive cases of laparoscopic pyloruspreserving pancreatoduodenectomy: improvement with surgical experience. Surg Endosc. 2013;27(1):95-103. doi: 10.1007/ s00464-012-2427-9.

8. Song KB, Kim SC, Hwang DW, Lee JH, Lee DJ, Lee JW, Park KM, Lee YJ. Matched case-control analysis comparing laparoscopic and open pylorus-preserving pancreaticoduodenectomy in patients with periampullary tumors. Ann Surg. 2015;262(1):146-55. doi: 10.1097/ SLA.0000000000001079.

9. Wellner UF, Küsters S, Sick O, Busch C, Bausch D, Bronsert P, Hopt UT, Karcz KW, Keck T. Hybrid laparoscopic versus open pyloruspreserving pancreatoduodenectomy: retrospective matched case comparison in 80 patients. Langenbecks Arch Surg. 2014;399(7):849-56. doi: 10.1007/s00423014-1236-0.

10.Zhang YC, Cai YQ, Gao P. Safety and feasibility of pylorus preserving laparoscopic pancreaticoduodenectomy. J Reg Anat Oper Surg. 2017;26(5):348-51.

11. Cho $A$, Yamamoto $H$, Nagata $M$, Takiguchi N, Shimada H, Kainuma O, Souda H, Gunji H, Miyazaki A, Ikeda A, Tohma T, Matsumoto I. Comparison of laparoscopy-assisted and open pyloruspreserving pancreaticoduodenectomy for periampullary disease. Am J Surg. 2009;198(3):445-9. doi: 10.1016/j. amjsurg.2008.12.025.

12.Shin SH, Kim YJ, Song KB, Kim SR, Hwang DW, Lee JH, Park KM, Lee YJ, Jun E, Kim SC. Totally laparoscopic or robot-assisted pancreaticoduodenectomy versus open surgery for periampullary neoplasms: separate systematic reviews and metaanalyses. Surg Endosc. 2016 Dec 30. doi: 10.1007/s00464-016-5395-7.

13.Lei P, Wei B, Guo W, Wei H. Minimally invasive surgical approach compared with open pancreaticoduodenectomy: a systematic review and meta-analysis on the 
feasibility and safety. Surg Laparosc Endosc Percutan Tech. 2014;24(4):296-305. doi: 10.1097/SLE.0000000000000054.

14.Pędziwiatr $M$, Małczak $P$, Pisarska $M$, Major P, Wysocki M, Stefura T5, Budzyński A. Minimally invasive versus open pancreatoduodenectomy - systematic review and meta-analysis. Langenbecks Arch Surg. 2017;402(5):841-51. doi: 10.1007/ s00423-017-1583-8.

15.Ricci C, Casadei R, Taffurelli G, Pacilio CA, Ricciardiello M, Minni F. Minimally Invasive Pancreaticoduodenectomy: What is the best "choice"? A systematic review and network meta-analysis of non-randomized comparative studies. World J Surg. 2017 Aug 10. doi: 10.1007/s00268-017-4180-7

16. Correa-Gallego C, Dinkelspiel HE, Sulimanoff I, Fisher S, Viñuela EF, Kingham TP, Fong $\mathrm{Y}$, DeMatteo RP, D'Angelica MI, Jarnagin WR, Allen PJ. Minimally-invasive vs open pancreaticoduodenectomy: systematic review and meta-analysis. J Am Coll Surg. 2014;218(1):129-39. doi: 10.1016/j. jamcollsurg.2013.09.005.

17.Varela JE, Wilson SE, Nguyen NT. Laparoscopic surgery significantly reduces surgical-site infections compared with open surgery. Surg Endosc. 2010;24(2):270-76. doi: 10.1007/s00464-009-0569-1.

\section{Correspondence:}

Dr Jing Kong

Department of Biliary and Minimally Invasive Surgery

China Medical University Shengjing Hospital

Shenyang, No. 36, San Hao Street, Shenyang

110004 Liaoning China

kongjing1998@163.com

Received: Sep 13, 2017

Review: Nov 16, 2017

Accepted: Dec 15, 2017
Conflict of interest: none

Financial source: none

\begin{abstract}
${ }^{1}$ Research performed at Department of Biliary and Minimally Invasive Surgery, China Medical University Shengjing Hospital Shenyang, Liaoning, China.
\end{abstract}

